\title{
From the unity of the proposition to linguistic idealism
}

\author{
Richard Gaskin ${ }^{1}$
}

Received: 9 November 2015 / Accepted: 23 March 2016 / Published online: 22 April 2016

(C) The Author(s) 2016. This article is published with open access at Springerlink.com

\begin{abstract}
The paper contains a general argument for linguistic idealism, which it approaches by way of some considerations relating to the unity of the proposition and Tractarian metaphysics. Language exhibits a function-argument structure, but does it do so because it is reflecting how things are in the world, or does the relation of dependence run in the other direction (or in neither)? The paper argues that the general structure of the world is asymmetrically dependent on a metaphysically (though not historically) prior fact about language, namely that it exhibits subject-predicate (in general: function-argument) structure.
\end{abstract}

Keywords Linguistic idealism · Proposition · Unity · World · Language

\section{Linguistic idealism: general}

In The unity of the proposition (2008) and elsewhere I have sought to promote a position which I call 'linguistic idealism'. According to this view, the world is essentially a precipitate of language, or (in a different metaphor) the internal accusative of language. Less figuratively, the doctrine holds that the world consists of true and false Russellian propositions, presented by true and false declarative sentences mediated by true and false Fregean Thoughts. The existence of symbolic language is taken to be metaphysically given, and the truth or falsity of declarative sentences is likewise to be regarded as fundamental. To the extent (a very large extent) that the truth-values of sentences are not of our determining, linguistic idealism is compatible with, and

$\triangle$ Richard Gaskin

r.m.gaskin@liv.ac.uk

1 Department of Philosophy, University of Liverpool, Mulberry Court, Mulberry Street, Liverpool L7 7EZ, UK 
indeed involves, an empirical realism: that is to say, it envisages the world to contain (by in part consisting of) a range of facts, which on my approach are simply identified with true propositions, ${ }^{1}$ and these true propositions possess their truth-values for reasons that do not, in general, depend upon our say-so (similarly for the false propositions that make up the rest of the world).

So on this approach we start, as indicated, with sentences as the metaphysically given. Words, as semantically significant parts of sentences, are abstracted, or transcendentally deduced, from sentences 'horizontally': that is, the abstraction proceeds without leaving the level of symbolic language. Levels of sense and reference are then transcendentally deduced in a 'vertical' direction both for sentences and for their semantically significant parts. ${ }^{2}$ The referent of a linguistic expression is that thing (to put it neutrally) which someone needs to cognize, and cognize as such, in order to count as understanding the expression, and the sense of an expression is (following Frege) a mode of presentation of the referent. The idea is that the transcendental deductions in both horizontal and vertical directions are forced on us by the phenomena of speakers' understanding of, and their creativity with, language. These phenomena require us, as theorists, to discern semantically significant structure in sentences, and to assign meanings (themselves factored into sense and reference components) to sentences and to their semantically significant parts. So, for example, we may discern in sentences such parts as proper names and concept-words or general terms, and these linguistic items have objects and concepts or properties as referents respectively, with, as mentioned, a mediating level at which senses of proper names and of concept-words or general terms are housed. The objects and the concepts or properties that we ordinarily take to make up the world are indeed in the world, but they are there by courtesy of their figuring in true and false propositions. Those objects and properties, and the propositions they go to compose, are essentially meanings-more precisely, referents. One naturally speaks of objects and properties - including relations - as though they were different types of thing, and for some purposes it makes sense to draw these distinctions; but at a higher level of generality all referents - that is, all things, whether concrete or abstract, individual or general-may be thought of as objects, and the words that refer to them as names. From that lofty perspective the sentence is seen to be a collection of names. ${ }^{3}$ That immediately throws up the traditional unity problem: what distinguishes a mere bunch of names from a sentence apt to take a truth-value? I shall return to this in Sect. 3.

On the linguistic idealist's approach, reference figures as a theoretical relation, and referents as posits. The world itself, in this picture, emerges as a theoretical posit, consisting in the first instance of true and false propositions, which are the referents of true and false declarative sentences respectively, and then derivatively it is made up of objects and properties, which are the referents of the different kinds of word discerned by the horizontal process of abstraction described above, and are the constituents of propositions. All this theoretically driven positing arises, as mentioned, from the

\footnotetext{
1 See on this point Gaskin (2015).

2 See Gaskin (2008, §9).

3 See Gaskin (2008, esp. §40; 2013).
} 
need to provide an explanatory model of the nature of communicative language. It is worth noting here that the idea that reference should be thought of as a theoretical relation - and, correspondingly, that ontology is derivative of language-is by no means a novel one. It is a position that is common to W. V. Quine, Donald Davidson, and John McDowell, who all propound the view that sentences are metaphysically and semantically basic, and that the notion of reference is then introduced, in a distinctively theoretical move, to help us conceptualize what goes on when speakers interpretthat is, understand-sentences. ${ }^{4}$ The idea that language determines ontology is also a distinctive feature of the so-called neo-Fregean programme, defended in numerous publications by Bob Hale and Crispin Wright, who trace its philosophical inspiration to Frege's Context Principle. On this approach, there is no more to being an object than being the referent of a proper name, identified as such by language-internal tests. ${ }^{5}$

\section{Linguistic idealism in the Tractatus}

In the Tractatus Wittgenstein embraced a version of linguistic idealism, in the sense of that phrase which was operative in Sect. 1. The Tractarian world consists of true and false propositions, which are arrangements of objects; these propositions are constitutively the referents of sentences, which are arrangements of names. Since Wittgenstein transcendentally deduces the existence of objects from the meaningfulness of language (2.02-2.0212, 3.23), we know that he thinks that, metaphysically speaking, language comes first. ${ }^{6}$ Of course I have just expressed Wittgenstein's view in terms other than his own. Wittgenstein does not use the word 'proposition' in the Tractatus: that is, he does not use the German words 'Proposition' or 'Aussage'. He talks about sentences (Sätze) on the one hand, and states of affairs (Sachverhalte, occasionally Sachlagen) or facts (Tatsachen) on the other. He distinguishes between names and sentences on the basis that names (and not sentences) have reference, whereas sentences (and not names) makes assertions. ${ }^{7}$ Wittgenstein has his own reasons for making this distinction, but, if his position is transposed into my terms (Sect. 1), it does not falsify the interpretation of the Tractatus if we suppose that, in one sense of the word 'proposition' now philosophically current, according to which it means the referent of a declarative sentence, Wittgenstein thinks that declarative sentences refer to propositions, which

\footnotetext{
4 For Quine, see e.g. 1960, §6; 1977, pp. 190-191; for Davidson, see 1984 passim, esp. pp. 74, 133137, 193, 208-210, 219-225 (at p. 221 the reader should consult the original printing of the essay for two paragraphs omitted by oversight in the 1984 reprint: Davidson (1980, p. 136); cf. Schantz (1996, p. 178n.1)), pp. 235-236; 1990, pp. 299-300; 2001, pp. 131-134; 2005, pp. 34-36; for McDowell, see 1998a, pp. 144-149, 196-198; cf. 1997, pp. 158-159 with n. 1; 1998b, pp. 40-41. See further Gaskin (2006, Chap. VI; 2008, $\S 9,53)$.

5 See Hale (2010), with full bibliography. Especially noteworthy are Wright (1983), Hale (1987), and various papers collected in Hale and Wright (2001).

6 The precise interpretation of these passages is controversial: for discussion see, e.g., Simons (1985, pp. 213-215); Proops (2004); White (2006, pp. 38-44); Morris (2008, pp. 355-363). But, whatever the details, it seems beyond doubt that Wittgenstein intends a transcendental deduction that has the general form that state in the text.

$71922 \S \S 3.142 .3 .144,3.202-3.221$. Note that in 3.144 'described' must be tantamount to 'asserted': see Sellars (1963, p. 240).
} 
are to be identified with obtaining or non-obtaining states of affairs, the former of these in turn being identified with facts.

Now officially Wittgenstein identifies the world with just the true propositions or obtaining states of affairs: that is how the Tractatus famously opens (1-1.13). And the claim is repeated at 2.04. But almost immediately after that, in 2.06, we are told that the true and false propositions (in my sense) together (that is, all the states of affairs, obtaining and non-obtaining) are to be identified with reality (die Wirklichkeit), and in a revealing inconsistency with his official position Wittgenstein then informs us that 'the total reality' is 'the world' (die gesamte Wirklichkeit ist die Welt: 2.063), which takes us back to the kind of linguistic idealism already set out, in which the world is identified with all the propositions, not just the true ones. ${ }^{8}$ It might be objected here that in pinning the inconsistency on Wittgenstein I have conflated the obtaining or nonobtaining of states of affairs (2.06) with obtaining or non-obtaining states of affairs; but the conflation is one that Wittgenstein makes himself, in 2, where we are told that 'the fact' is 'the obtaining of states of affairs'. So, availing ourselves of Wittgenstein's own distinction between positive and negative facts (2.06), the inconsistency into which Wittgenstein falls is the following triad: (i) the world is the totality of positive facts $(1,2,2.04)$; (ii) the reality is the totality of positive and negative facts (2.06); (iii) the world is the reality (2.063).

Of course, one can be sympathetic to the linguistic idealism of the Tractatus, in its general form, without endorsing all aspects of Tractarian philosophy of language and metaphysics: in particular, the picture theory, though acceptable to the linguistic idealist in broad outline-for it is certainly part of that doctrine to suppose that there is some kind of match in form between language and the world-arguably goes wrong in detail. The theory can be represented as starting from the plausible enough idea that sentences share logical form with reality (2.18): that is, the sentence comprises components (names) which are arranged in a particular way, and that arrangement of names conveys that things - the referents of the names - are arranged on the ground in a certain way. So far, one might think, so anodyne, even for someone not attracted by linguistic idealism. The mistake Wittgenstein arguably makes at this point is to try to spatialize the linguistic and worldly structures that are being said to mirror one another, for it is obvious that sentences do not in general share spatial form with the depicted reality. ${ }^{9}$ But the Tractatus does contain a more promising way of thinking about what connects linguistic and worldly structures, namely the thought that "where there is composition, there is argument and function' (5.47). So we might say that the essence of the picture theory is the idea that language and reality share a common functional structure. Certainly this idea has proved fruitful in the study of language. For it is standard practice in modern linguistic theory to represent structure functionally. ${ }^{10}$ The familiar phrase markers of modern syntactic and semantic theory may be thought of in just such terms: we may conceive dominating (non-terminal) nodes as representing the value of a function applied to the objects (including properties, relations, and

\footnotetext{
8 See Stenius (1960, pp. 50-52).

9 For detailed argument on this point see Gaskin (2009).

10 A good text is Heim and Kratzer (1998).
} 
connectives) located at their daughter nodes, taken as arguments. On this approach we may think of sentences and propositions as sharing a function-argument manner of composition.

I want in this paper to offer a general argument for linguistic idealism, one that is free of the controversial metaphysics of the Tractatus, but which takes its cue from what one might consider the acceptable core of the picture theory, namely the thought that linguistic structures are capable of saying how things are in the world by virtue of composing elements in a functional way, the functional nature of the composition of these structures being mirrored by organizations of objects (of all sorts, so including properties etc.) on the ground (that is, in the expressed proposition, in the world). Now Wittgenstein's position in the Tractatus is that there is an explanatory asymmetry in the mirroring relation between language and world, with language taking priority. This is also the answer that my linguistic idealist gives. So if we ask the question 'Does language exhibit function-argument structure because the world does, or vice versa, or neither?', the answer that both Wittgenstein and my linguistic idealist give is that 'vice versa' is right: the function-argument structure displayed by organizations of objects (in the widest sense) in the world drops out—is a precipitate —of isomorphic linguistic structures.

\section{Unity, subject and predicate, function and argument}

The question posed at the end of the last section is sometimes phrased in the following terms. As I mentioned in Sect. 1, we often think of the world as, roughly speaking, divided into what are called 'objects' and 'properties' (the latter term including relations); speakers talk about these in sentences that are parsed into subjects and predicates (of different 'arities'). We then ask the question: which comes first, philosophically speaking? Does language have a subject-predicate distinction because the world has an object-property distinction, or vice versa (or neither)? This way of putting the matter, though conventional, is potentially misleading in a way that is avoided by speaking instead in terms of function and argument. For to talk of an object-property dichotomy might seem to imply that properties are not objects. But, as suggested earlier, there is a good sense in which, at a higher level of generality, properties are objects. Frege, of course, rejected the objectual status of concepts (which for present purposes we need not distinguish from properties), encapsulating this rejection in his distinction between saturated, or complete, objects on the one hand, and unsaturated, or incomplete, concepts on the other. But that policy landed him, as is well known, in paradox, and it seems better to admit that there is no good sense in which properties, or what Frege called 'concepts', can be distinguished from what he called 'objects' in point of saturatedness or unsaturatedness. Since we do not want to jettison the category of the objectual, we are left with no alternative but to classify concepts as objects (of a particular kind), rather than as not objects at all. If we nevertheless wish to retain his chemical metaphor, Frege's own context principle then obliges us to say that all objects are unsaturated, and correspondingly that (in an older terminology) all words are syncategorematic. Since, again, we do not want to drop the category of name, and given that all words turn out not to differ from bona fide proper names in point 
of (un)saturatedness - they are all alike unsaturated, or incomplete-we may as well say that all words are names. Of course, what matters here is not the particular labels we jettison or retain (in the latter case, I have suggested, 'object' and 'name'), but the fact that the Fregean metaphor of unsaturatedness, and the older terminology of syncategorematicity, apply uniformly to all words and their referents. ${ }^{11}$

Saying that all words are names has been thought by many to block the path to solving the problem of the unity of the proposition: it has been held that if all words are names, the sentence will degenerate into a mere list. But this is incorrect. The easiest way to see that an asymmetry between saturated and unsaturated subsentential components, and correspondingly between their respective referents (objects and concepts, in Frege's terminology), cannot be the key that unlocks a solution to the unity problem, is this: we can construct languages whose sentences consist of words of the same syntactic type-whose words are all indisputably names, in fact. To fix ideas, let us assume that these names all have maximal combinatorial freedom: that is, a well-formed sentence can be constructed, in this hypothetical language, from any (number of) names in any combination. (Plausibly, that was how Wittgenstein in the Tractatus conceived of his fully analysed sentences.) To fix ideas, suppose we have a language suitable for describing linear arrangements of dots. The language contains names (say, ' $a$ ', ' $b$ ', etc.) referring to individual dots, and sentences are formed by concatenating names linearly, it being understood (in accordance with Wittgenstein's picture theory) that sentences assert, in their spatial arrangement of the names, a correlative arrangement of dots 'on the ground': so the sentence ' $a b c$ ', for example, would say that $b$ is between $a$ and $c$. Even so, there is a conceptual distinction to be drawn between sentences so generated, consisting exclusively of items that are, on anyone's view, names, and mere lists of exactly the same names. Of course a sentence of this hypothesized language will present the same appearance as an equiform list; that is, the written sentence will look just like the written list, and (we can suppose) the spoken form of the one sound just like the spoken form of the other. But that does not entail that there is no theoretical distinction to be drawn between sentence and list, and it is clear that there is such a distinction. The semantics of a sentence will be different from the semantics of a list: for a start, a sentence (assuming that it is a declarative sentence) will have a truth-value, whereas a list will not. But we can still ask: what makes the difference between sentence and list?

It follows from the way we have set up our hypothetical language that what unifies its sentences, and distinguishes them from equiform mere lists, cannot lie in differential syntactic properties of the component words, for these words all have exactly the same syntactic properties, that of maximal combinatorial freedom. ${ }^{12}$ Sentence and list are of course distinguished by their deep syntax: but saying this does not get us very far, for the fact that sentence and list have different deep syntactic properties just follows from the fact that one is a sentence and the other a list: like the fact that they have different semantic properties, it does not tell us what the difference consists in. What is it for a bunch of words to have the semantics, and deep syntax, of a sentence, as

\footnotetext{
11 For detailed argument on the points in this paragraph, see Gaskin (2008, Chap. 3).

12 See on this point Gaskin $(2008, \S \S 5,62,88)$.
} 
opposed to a list? The unity issue is not a matter, either, of distinguishing interpretable linguistic structures from uninterpretable ones, of saying why some structures are interpretable and others not. ${ }^{13}$ For, even if we restrict our attention to interpretable structures, there is still a distinction to be drawn between a sentence and a mere list, because you cannot stop people listing words which, if put together in that way, are also capable of forming an interpretable sentence. So the unity problem does not end with a well-formed sentence; it starts there. The problem is this: given that we have before us a linguistic structure that might be either a sentence or a list (is interpretable in either way), what determines which of these it is? Or: what is it for us to treat it as the one rather than the other?

To give an answer to this last question in terms of, say, the syntactic operation Merge ${ }^{14}$ would be vacuous, for the question precisely is: what is it for syntactic structures to be merged in the right way to form a sentence? You do not solve the unity problem by announcing the discovery of a wonderful syntactic operation, helpfully called 'Merge' — nomen est omen - whose magical property is to take two separate items and form them into a unity. For the question will simply remain: how does it manage to do that? Just having a pregnant label does not seem to be quite enough. What, in the first instance, makes the difference between a sentence and a list (correspondingly between a proposition and a mere aggregate of objects) is, to put it telegraphically, that the predicate in the sentence is actually predicated of the subject, not merely (say) concatenated with it, or, to put the point in terms of the function-argument model, we might say that what makes the above difference is that, in the expressed proposition, the function is actually applied to its argument(s). Note that this does not entail that the relevant sentence is automatically true: in a false sentence, too, the function is actually applied to its argument(s); the function is applied to its argument(s) in the designated proposition, be that proposition true or false. If, for example, the sentence 'Socrates is foolish' is false, the proposition to which it refers-namely, the proposition that Socrates is foolish - is an entity in which a function (the property of being foolish, as it might be) is actually applied to the argument (the man Socrates) to yield the resulting (but, as it happens, false) unified proposition that Socrates is foolish. The truth-value of a proposition has nothing to do with the success of functional application: that success does not in any way entail truth. But talk of functional application is not the end of the explanatory road. We can ask what, in turn, that functional application consists in. But for my present purposes that is as far as we need to take the matter here. ${ }^{15}$

Given, now, that we can construct languages whose sentences are exclusively composed of type-identical names, and which therefore appear to lack a subject-predicate distinction, it might seem to follow that the question whether language has a subjectpredicate distinction because the world has an object-property distinction, or vice versa, is not posed in the most general terms possible. Perhaps the question should be

\footnotetext{
13 So Collins (2011, pp. 70-71, 109, and passim).

14 So Collins (2011).

15 See further Gaskin (2008, Chap. 6), where I argue that what makes the difference between sentence and list is, in brief, that analysis of the proposition that is the referent of a unified sentence generates a certain structural regress-a version of Bradley's regress-whereas the analysis of a mere aggregate of objects does not.
} 
posed in terms of the function-argument distinction rather than the subject-predicate one. But there is a terminological subtlety that needs to be registered here. So far in the discussion I have been tacitly assuming that by 'subject' and 'predicate' we mean grammatical subject and predicate, and on that basis it is true to say that to pose our question in terms of the subject-predicate distinction is not to pose it in the most general terms possible. But more abstract notions of subject and predicate are available. In the sentence 'Someone killed Kennedy', traditional grammar identifies 'someone' as the subject, and 'killed Kennedy' (or just 'killed') as the predicate. Frege, however, while agreeing with traditional grammar that 'killed Kennedy' in the above sentence is a predicate, precisified its status by identifying it as a first-level predicate, and he analysed 'someone' as a second-level predicate (or first-order quantifier). The levels relate to an envisaged syntactic description of the language which arranges expressions in a hierarchy; there is a corresponding semantic hierarchy (indeed there are corresponding hierarchies at both levels of sense and reference). ${ }^{16}$ Following this lead, we might distinguish between a sentence's analytical subject and predicate as follows: where a syntactically adequate description of a language discerns in a given sentence a subsentential expression of level $n$ constructed with another such expression of level $n+1$, the former expression counts as the sentence's analytical subject, and the latter as its analytical predicate. Since we may conceive of the relation between expressions of level $n$ and those of level $n+1$ with which they are constructed in function-argument terms - that is, the referent of the expression which is identified as being of level $n+1$ is a function taking the referent of the $n$-level expression as argument-it follows that, though it is true that to pose our governing question in terms of a grammatical subject-predicate distinction is not to pose it in its most general possible terms, when we think of a sentence as being divided into analytical subject and predicate we make good that deficit. For to ask whether the analytical subject-predicate distinction is beholden to the world, or imprints itself on the world (or neither), is to ask whether the function-argument structure of language comes from the world or is the template for worldly structures (or neither). These two ways of posing the question are just notational variants.

It follows that the question we are asking is, from a grammatical point of view, highly abstract. In particular, it is not tied to any asymmetry between grammatical subject and predicate such as is exhibited by natural languages like English and German. A language that exhibited no such asymmetry, such the fully analysed language of the Tractatus, which consists of sentences composed of type-identical names, and any artificial (or indeed natural) language whose sentences were similarly constructed, would throw up exactly the same question. That is because any such syntactically uniform language will still exhibit an analytical, though not a grammatical, subjectpredicate asymmetry; or, equivalently, we can say that any such language will still deploy functional structures. Wittgenstein acknowledges this point for his own fully analysed language, when he remarks at Tractatus 5.47 that

All logical operations are indeed already contained in the elementary sentence. For ' $f a$ ' says the same as ' $(\exists x) \cdot f x \cdot x=a$ '. Where there is composition, there

16 See Dummett (1981, Chap. 3); Gaskin (2008, Chap. 4). 
is argument and function, and where these are, all logical constants are already present. (tr. Ogden, adapted)

In representing an elementary sentence as ' $f a$ ', Wittgenstein is in effect recognizing the analytical subject-predicate distinction: for ' $f$ ' is not a simple name, so this notation must be shorthand for something like the situation in which an elementary sentence such as ' $a b c$ ', where ' $a$ ', ' $b$ ', and ' $c$ ' are simple names, is analysed as containing a subject term ' $a$ ' and a predicate ' $b c$ '. (The availability of this analysis does not block alternative analyses, in which ' $b$ ' figures as the subject and ' $a \ldots c$ ' as the predicate, and so on.) Whether Wittgenstein's programme of analysis has any chance of success is not the issue here: even if it fails, we should leave conceptual space for the possibility that a language might consist exclusively of type-identical names. After all, even if Wittgenstein's projected fully analysed language, which would be one such language, is not available as a realistic option, we can certainly, as noted, construct artificial languages which do exhibit the requisite grammatical symmetry. The point I am making here is that such languages will still, at the analytical level, exhibit a subject-predicate asymmetry; they will still use functional structures. Our governing question therefore applies to any language, whether or not it incorporates a grammatical subject-predicate asymmetry in its structures, so long as we take the analytical subject-predicate asymmetry into account.

\section{A transcendentalist argument for linguistic idealism}

In the Tractatus, Wittgenstein claimed that the general form of the sentence could be conveyed in the words 'This is how things are' (Es verhält sich so und so: 4.5). He meant this characterization to apply to any (declarative) sentence. So it applies not merely to sentences of natural languages like English and German, but also to fully analysed sentences, as he conceived them, or indeed to sentences of artificial languages deploying type-identical names. Of course, when we express, in these very general terms, what any declarative sentence says, we perforce do so in our language, which (in the case of English or German) evinces a grammatical subject-predicate asymmetry. If we suppose that ' $a b c$ ' is a declarative sentence comprising type-identical namesperhaps a Wittgensteinian elementary sentence, or a sentence of the artificial language sketched above - then in conveying its general content in the words 'This is how things are', we say what that sentence (in general) says, but in a different way. We cannot convey in English or German or in any language in which a grammatical subjectpredicate distinction is embedded how a sentence such as we are envisaging ' $a b c$ ' to be says what it says; but we can convey what it says. Suppose that, in accordance with Wittgenstein's picture theory, it says in more detail that $b$ is between $a$ and $c$ : well then, I have just conveyed what ' $a b c$ ' says, though I have done it in a different way from the way in which ' $a b c$ ' itself achieves its meaning. For our purposes, commonality of reference, not difference of sense, is the crucial point.

With these considerations in mind, we may resume our question either in its original formulation-'Does language exhibit function-argument structure because the world does, or vice versa, or neither?' - or in the alternative, but equivalent, version: 'Does language exhibit an analytical subject-predicate distinction because the world has an 
(analytical) object-property distinction, or vice versa, or neither?'. We can make this issue vivid by reflecting on the extreme locality of empirical language. Let us recall some familiar facts about our evolutionary history:

Fling your arms wide in an expansive gesture to span all of evolution from its origin at your left fingertip to today at your right fingertip. All across your midline to well past your right shoulder, life consists of nothing but bacteria. Many-celled, invertebrate life flowers somewhere around your right elbow. The dinosaurs originate in the middle of your right palm, and go extinct around your last finger joint. The whole history of Homo sapiens and our predecessor Homo erectus is contained in the thickness of one nail clipping. As for recorded history; as for the Sumerians, the Babylonians, the Jewish patriarchs, the dynasties of Pharaohs, the legions of Rome, the Christian Fathers, the Laws of the Medes and Persians which never change; as for Troy and the Greeks, Helen and Achilles and Agamemnon dead; as for Napoleon and Hitler, the Beatles and Bill Clinton, they and everyone that knew them are blown away in the dust of one light stroke of a nail-file. (Dawkins 1998, pp. 12-13)

The reader will no doubt have already encountered this analogy or similar ones; they give rise to many thoughts about many things. The thought that interests me here is the following. Language has evolved, and is accordingly of very recent and local origin, and yet it appears to be omnicompetent: certainly it can describe remote regions of space and time. For example, nothing seems easier than to talk, as Richard Dawkins does in the quoted passage, of a time when language was not. How is this possible?

At this point anyone trained in philosophy naturally reaches for one of two answers: either an empiricist or a transcendentalist one. These answers correspond to opposite orders of metaphysical priority. According to the empiricist approach, worldly structures drive linguistic structures; there is an (analytical) subject-predicate distinction because there is an (analytical) object-property distinction. Language is competent because it has evolved to be competent. Compare the question: How/Why is it that we are able to pick things up with our hands? The answer to this question is supplied by evolutionary theory, and a thoroughgoing empiricist will maintain that our question about language should also receive an evolutionary answer. By contrast, a transcendentalist will reply to our governing question that linguistic structures drive worldly structures; there is an object-property distinction because there is a subject-predicate distinction. Language is competent because it has to be competent, and this for logical or metaphysical, not empirical, reasons. Anything that language could not describe would not be a world; the possibility of a world that is not describable by language can be ruled out a priori. Here we may compare the question: How/Why is it that $67+58=125$ ? Unless you are an empiricist about mathematics, you will think that sixty-seven and fifty-eight added together make one hundred and twenty-five because they have to do so, as a matter of logical or metaphysical necessity: any other result would not be the result of applying exactly the function of addition to exactly those two numbers.

Which answer is better? I believe that we should reply that the transcendentalist's answer is better, for the following reason. An empiricist is forced to hold that our confidence in language's competence is merely inductively based, so that we cannot 
a priori rule out the conceivability of scenarios in which there is a stretch of reality that language cannot describe, just as, for the empiricist about mathematics, we cannot a priori rule out the conceivability of a scenario in which sixty-seven and fiftyeight added together do not make one hundred and twenty-five. But the supposition that our confidence in language's competence might be merely inductively based is unacceptable: it makes theoretical room for a scenario in which there is supposedly a stretch of reality to which language does not apply; but if language really does not apply to it, how can it be a stretch of reality? For something to be a stretch of reality there must be a way things are there: but saying that much already involves a minimal application of language, and we are already asserting that the subject-predicate distinction - at least the analytical subject-predicate distinction, if not the grammatical one-applies to our would-be stretch of reality. So the empiricist position is selfundermining: it is obliged to try and make sense of a situation that in fact does not make sense.

This argument will no doubt seem rather quick; so let us unpack it a bit. Instead of talking generally about language's applying, or not, let us talk about a particular language's applying, or not, to a stretch of reality. The idea of a particular language's applying to a stretch of reality is essentially the idea that that language contains declarative sentences some of which are true. A declarative sentence says how things are; if it is true, then things really are the way it says they are. And the idea of a stretch of reality is the idea of a region where things are a certain way. (Note that the plural formulation here does not need to be taken too seriously: it is absent in the German equivalent that Wittgenstein employs in the Tractatus:es verhält sich so und so. So we might say that the idea of a stretch of reality is the idea of a region where something is, or some things are, a certain way. But I will continue to employ the plural for convenience.) Now the problem for our envisaged empiricists is this: they have to be able to make sense of the possibility that there might be a scenario in which things really are a certain way in a region of the world, but in which there is no sentence, or set of sentences, saying that things are that way, so describing that stretch of reality truly. But the minimal sentence 'Things are, in this scenario, a certain way' will itself do the trick of (minimally) describing that stretch of reality, assuming that the reference of the demonstrative is appropriately secured. In effect, an empiricist requires the possibility of a scenario in which things are a certain way but in which language cannot say that they are a certain way, and that possibility is self-contradictory.

At this point a Humean, or perhaps a quasi-realist (in Simon Blackburn's sense) ${ }^{17}$ might try the following manoeuvre. Suppose that it is agreed on all sides that we humans have evolved in such a way as not to be able to make sense of the idea of a stretch of reality to which language does not apply. The quasi-realist now takes this to be the fundamental fact. For the quasi-realist, it is not that we have evolved in that way because the world has forced us, in any logical or metaphysical sense, so to evolve; our beliefs are not a reflection of necessities that are brutely out there in the world. Out there in the world there is only contingency, but our causal interaction with the world

17 See his 1984 and 1993. 
is such that we project necessities onto it. Having made these projections we develop a phenomenology which gives us the impression that the projected necessities are in fact objectively there in the world; but, says the quasi-realist, that move is a mistake, and appearances mislead us as to the real facts of the matter. It may even be true, the quasi-realist will concede, that we have evolved in such a way that we cannot avoid descrying necessities in the world. Still, the Humean philosopher, resiling from this whole process and viewing it sideways on, can see from the vantage point of his or her philosophical armchair that these necessities are not really there-not really there, not in the world.

The problem with this strategy resides in its split-level approach. On the one hand there is the vulgar, on the other there are the philosophers; over there we have ordinary people trapped in a metaphysics whose aetiology they do discern; over here we have the philosophers who have broken the code, and so who have escaped from the vulgar mindset. But if the philosophers can achieve insight, what is stopping the vulgar from doing the same? Give them the requisite mental equipment together with copies of Blackburn's books, and they should be able to do it. In principle nothing prevents everyone from becoming quasi-realists. But then the position is inherently unstable: for either it must collapse to an ordinary empiricism which simply says that there are no necessities in the world - that is what the quasi-realist really thinks - and anyone who denies this simply needs education; or it goes the other way and transcendentalizes itself. In the latter scenario, instead of the vulgar's joining the philosophers, the philosophers make one with the vulgar and admit that the grip of evolutionary history on us all is such that we simply cannot make sense of the idea that the world might only contain contingencies. But this position, if it is adopted without any mental reservation-that is, assuming that the philosophers do not tacitly say to themselves, 'Of course, contingency is all there really is', which would be self-contradictory-is tantamount to a realism that discovers necessities in the world. So the quasi-realist does not present us with a genuine alternative to empiricism and transcendentalism. There is no third way.

\section{Transcendentalism and verificationism}

It is important to be clear that the transcendentalist argument I have offered is not verificationist in the way that Davidson's rather similar transcendental argument is verificationist. Davidson holds that we can make no sense of a conceptual scheme which is fundamentally distinct from ours or, equivalently, that we can make no sense of a language that cannot be translated into ours. ${ }^{18}$ But in what sense can we make no sense of these possibilities? Can we make no sense of them because, were they to arise, we would not be able to tell that they had arisen? But then, as Adrian Haddock objects: 'how can it follow from there being no way of telling whether an $F$ is a $G$ that that the idea of an $F$ 's being a $G$ makes no sense? Surely it can only be true that there is no way of knowing whether an $F$ is a $G$ if the idea of an $F$ 's being a $G$ makes some sort of sense?' (2011, p. 36). To help Davidson out at this point, we

18 See Davidson (1984, esp. essay 13). 
need to construe talk of 'making sense' as shorthand for the absence of contradiction. So Davidson's argument would be to the effect that it is contradictory to suppose that there might be, say, an untranslatable language. The problem with this version of Davidson's position is that it does not appear to be contradictory to posit such a language. One might interpose here that, in such a scenario, we would have no reason to call this untranslatable thing a 'language'. That is true. However, it only follows from this point that the untranslatable thing would not actually be a language if we are allowed to adduce a version of the verification principle, and say that for something to count as a language, we have to be able to recognize it as such. But what is the justification for that extra premiss?

By contrast with Davidson's argument, the case made by my transcendentalist is not a verificationist one. What my transcendentalist contends is that, for something to count as a stretch of reality, the subject-predicate distinction (at least the analytical such distinction) has to apply to it, and this conclusion is secured, as we saw Davidson's transcendentalist conclusion was not, by the contradictory status of the alternative. For if something is a stretch of reality, the subject-predicate distinction already applies to it: in saying that it is a stretch of reality we apply that distinction (indeed we apply the distinction in its grammatical manifestation). As I have noted, for something to be a stretch of reality, or a piece of the world, it has to be a way things are, and that fact guarantees an application of language as such to it. ${ }^{19}$ So while it is perhaps possible to make sense of the idea that there is a stretch of reality which is describable in a language that we cannot translate, it is not possible to make sense of the idea of a stretch of reality that is simply inaccessible to language as such - that is, of a stretch of reality that no language is capable of describing. Now language constitutively is, or involves, a way of saying how things are. Davidson is wrong to take the view that we do, or should, only count something as a language if we (human beings) can translate it: to say that is to fall into verificationism. But it is true-and it is a constitutive, not a verificationist, point - that something can only count as (that is, can only be) a language if it is, or involves, explicitly or implicitly, somehow or other, a means of saying how things are, truly or falsely. That in turn is tantamount to the following: any language consists (at least in part) of declarative sentences. Saying how things are, truly or falsely, is a fundamental property of language. So we have a fundamental connection between language and reality: reality is a way (or ways) things are, and as such is capable of being described in language as such; language is essentially a way of saying how things are.

If saying how things are, truly or falsely, is a fundamental property of language, then the declarative sentence, which is constitutively a truth-value bearer, is a fundamental 'move in the language game'. ${ }^{20}$ Being a bearer of truth-values is definitive of the declarative sentence, so long as we restrict our purview to items of symbolic language, but being truth-value bearers does not distinguish declarative sentences from all other things, because propositions are also truth-value bearers. As we have noted, a proposition, as the word is used nowadays by philosophers, is the meaning of a

19 Cf. Moore (1997, pp. 147-148).

20 There is a good case for holding that other types of sentence can be analysed as or reduced to declarative sentences: see Lewis (1976, pp. 37-44). 
declarative sentence; it is what that sentence semantically expresses. This involves at least the following: a sentence is a linguistic entity, that is to say, it has syntactic properties; propositions do not. Further, a sentence is an abstract object to which the type-token distinction applies: in the first instance, sentences are types, but they may be tokened-uttered, written, or merely thought—on an occasion of use. As types, sentences do not need to be tokened; indeed the number of sentences that never get tokened is far larger than the number of sentences that do get tokened. ${ }^{21}$ Propositions, by contrast with sentences, though they are, like sentences, abstract objects, do not admit of the type-token distinction. Propositions exist as abstract objects, but there are not different ways in which they can exist-merely abstractly, or in concrete instantiations. The relation between declarative sentences and propositions is on these points similar to that between numerals and numbers, or indeed between any words and their referents. And that is not surprising if, as was suggested above (Sect. 1), propositions are indeed the referents of declarative sentences.

\section{6 'The world as it is in itself'}

At this point the reader may be inclined to make the following quasi-Kantian objection. $^{22}$ The argument for linguistic idealism that I have given essentially works by attempting to force an opponent into asserting something self-contradictory, namely that there might be a stretch of reality which language cannot describe. This is selfcontradictory because as soon as the opponent starts talking about a stretch of reality, or a way things are, he or she has already started to describe it in language, and we have something that is apt for capture in any symbolizing system that has subject-predicate structure, or, in general, function-argument structure. But what if the opponent simply refuses to be drawn into making the offending assertion? In that case, the objector maintains, it might still be true that reality does not have the form of language; it is just that it cannot be said, on pain of contradiction. As soon as we start talking about reality we perforce give it the kind of shape that is apt for expression in language, but perhaps reality in itself does not have that shape. In effect the objector is accusing me of making the same mistake as Berkeley, when he tried to refute the possibility of existence unperceived by pinning a perception of the purportedly unperceived object on anyone who attempted to make the experiment, and in general by pinning a conception of the object on anyone who attempted to entertain its unconceived existence. On the objector's approach, while it is conceded that we talk about the world in language, and talk truly, it is not conceded that it follows that the world in itself has to share fundamental structure with language. Moreover, if the world-or some part of it-does not share fundamental structure with language, then (at least as far as these considerations go) it cannot be ruled out a priori, pace the linguistic idealist, that, although there are some bits of the world which we can talk about truly, there are other bits that cannot be captured in language at all.

\footnotetext{
21 See on this point Langendoen and Postal (1984).

22 See, e.g., Moore (1997, pp. 119-120).
} 
My response to this objection is to put pressure on the conception of the world in itself which is playing a key role in it. How can we make sense of that? As with Kant's noumenal realm, the problem is that we cannot. We are invited to suppose that the world in itself is, like the Kantian noumenal realm, indeed a world, and one which, on Kant's view, even contains objects, but it is supposed to be a world that, in itself, is not structured by categorial thought (including the categories of unity and plurality) and, crucially for our purposes, is not structured by language. If, nevertheless, it is conceded that we can somehow talk about the world, perhaps in so doing imposing (or trying to impose) a quasi-linguistic structure on it, how can that talk not be so much irrelevance? After all, whatever we are doing when we utter true or false sentences, we are not, apparently (according to the objector), talking about the world as it is in itself. But then how is it possible for our sentences to be true, or even false, at all? For the key point is that our sentences presuppose that the world has object-property structure: if the world does not - not really, not in itself-have that structure, then our sentences cannot have a truth-value. If we are imposing (or trying to impose) a structure on the world which in itself it does not have, our sentences should be nonsense. But this is quite unacceptable. Suppose I say that a cat is on a mat. ${ }^{23}$ This sentence will be true if an appropriate object has an appropriate property-if, in fact, there is a cat which is on a mat; and it will be false if no objects and properties are arrayed in the way the sentence says they are arrayed - if no cat is on any mat. Given suitable background conditions it is difficult to see how that sentence could simply be nonsense. That is, so long as the properties of cathood and mathood exist, and spatial relations exist, and the usual rules of English hold, the sentence is guaranteed meaningfulness. The sentence can only be nonsense if one or more of its component words lacks meaning, or if it breaches the rules of English syntax, or similar. It cannot be nonsense for some deeper reason, such as a fundamental inadequacy in language itself, so that it necessarily misses its target. And language would miss its target if, notwithstanding that it in a quotidian sense true that a cat is on a mat, or at worst false (because there are no cats or they are all otherwise engaged), the world in itself is not really so constituted that an object like a cat could be positioned in relation to another object such as mat, in such a way as to permit that relation to be expressed, truly or falsely, by subject-predicate discourse.

Look at it another way. The best that can accrue to our sample sentence, given suitable contextualization, is truth, and the worst that can befall it, modulo the same assumption, is falsity. If the sentence is true then it is true that a cat is on a mat, and if the sentence is false then it is false that a cat is on a mat. In both the best- and the worst-case scenarios our use of a sentence like 'a cat is on a mat' envisages a world with object-property structure, containing such states as that of a cat's being on a mat, or of no cat's being on any mat. There can be no contrasting idea of a world in itself - a world that, in itself, lacks that structure. Even the worst-case scenario for our sentence, falsity, is a significant achievement-the achievement of meaningfulness. Here one recalls Wittgenstein:

\footnotetext{
23 I have changed the usual philosophers' formulation - 'the cat is on the mat'-because I wish to abstract from problems connected with the semantics of definite descriptions.
} 
The agreement, the harmony, of thought and reality consists in this: if I say falsely that something is red, then, for all that, it isn't red [es doch immerhin nicht rot ist]. And when I want to explain the word 'red' to someone, in the sentence 'That is not red', I do it by pointing to something red. ${ }^{24}$

And again:

When ... we disapprove of the expressions of ordinary language (which are after all only performing their office), we have got a picture in our heads which conflicts with the picture of our ordinary way of speaking. Then we are tempted to say that our way of speaking does not describe the facts as they really are. As if, for example, the sentence 'He is in pain' could be false in some other way than by that man's not being in pain. As if the form of expression were saying something false even when the sentence faute de mieux asserted something true. ${ }^{25}$

The whole idea of the world as it is in itself - that is, the world conceived independently of any relation to linguistic representation, so that the subject-predicate structure of discourse makes some kind of fundamental descriptive error, even when we speak the truth-makes no sense, and accordingly the idea that the world in itself does not have object-property structure collapses. In declarative sentences, true or false, we necessarily presuppose that the world has object-property structure, and there is no getting behind that presupposition to find that, in itself, it does not have that structure, without thereby undermining the meaningfulness of those sentences. So I revert to my initial position: anything that is a world is (in itself) a way things are, and that already carries with it implicit object-property structure.

If my argument has been successful, it will have shown that the world is essentially expressible in language, for the reason given by the transcendentalist, namely that linguistic structures drive worldly structures. (Of course, nothing follows, just so far, about the knowability of the world.) That establishes a version of linguistic idealism. But what has been established, assuming that it has been established, is of course a highly abstract thesis: what does it mean in detail? Here, in conclusion, I can only give some general indications. One thing that the thesis means, as I have suggested, is that the declarative sentence is the linguistic item which makes the primary 'move in the language game'. That follows from the way in which the case for linguistic idealism was made: for the world's dependency on language was established by pointing out that a stretch of reality has to be a way things are (or a way something is), and that this is exactly what is conveyed by a declarative sentence. Once we have the primacy of the declarative sentence, what follows? At this point we may avail ourselves of the strategy outlined in Sect. 1. We have declarative sentences (and other kinds of sentence by construction from the declarative), and the theoretician now gets to work. This work proceeds, as indicated, both horizontally and vertically. Horizontally, as theoreticians we split the sentence up into semantically significant subsentential parts; vertically, we attach semantic significance to the sentence and its newly posited parts, as well as to the way they are put together: in brief, we write a lexicon and a grammar. We

24 1977, I, §429, tr. Anscombe. Cf. I, §§95, 402, 443, 447; 1973, 135; McDowell (1994, p. 27).
25 1977, I, §402, tr. Anscombe, adapted. 
then use the resulting structure to model our understanding of language. We divide the intuitive notion of meaning into two subcategories: sense and reference. The referent of a linguistic expression is that which an understander of that expression has to cognize, and cognize as such; the sense is the way in which that referential object is cognized. Both these ingredients are necessary if we are to theorize cogently about meaning. Propositions then emerge as the referents of declarative sentences: they are a superior candidate to truth-values, which Frege wanted for this role; and, if reference models understanding, it is evidently preferable to say that declarative sentences have reference than that they do not. ${ }^{26}$ Once we have propositions in place as the referents of declarative sentences, there is a good case for identifying the world with those propositions. In particular, it is unacceptable to try to construct the world out of entities located lower in the semantic hierarchy than propositions. Facts are the most popular choice to be such grounding entities, but if they are identical with true propositions, as was suggested in Sect. 1, they are not capable of grounding the truth of those propositions, for a proposition cannot ground its own truth. And objects, if located lower in the semantic hierarchy than propositions, would have to be Dinge an sichfor they would not be propositionally structured-a disposition which would take us back to the Kantian picture I have rejected.

Acknowledgements My thanks to the editors, the referees, and especially to Michael Morris, for their helpful comments on an earlier version of this paper.

Open Access This article is distributed under the terms of the Creative Commons Attribution 4.0 International License (http://creativecommons.org/licenses/by/4.0/), which permits unrestricted use, distribution, and reproduction in any medium, provided you give appropriate credit to the original author(s) and the source, provide a link to the Creative Commons license, and indicate if changes were made.

\section{References}

Blackburn, S. (1984). Spreading the word: Groundings in the philosophy of language. Oxford: Clarendon Press.

Blackburn, S. (1993). Essays in quasi-realism. Oxford: Oxford University Press.

Collins, J. (2011). The unity of linguistic meaning. Oxford: Oxford University Press.

Davidson, D. (1980). Reality without reference. In M. Platts (Ed.), Reference, truth and reality (pp. 131140). London: Routledge and Kegan Paul.

Davidson, D. (1984). Inquiries into truth and interpretation. Oxford: Clarendon Press.

Davidson, D. (1990). The structure and content of truth. Journal of Philosophy, 87, 279-328.

Davidson, D. (2001). Subjective, intersubjective, objective. Oxford: Clarendon Press.

Davidson, D. (2005). Truth and predication. Cambridge, MA: Belknap.

Dawkins, R. (1998). Unweaving the rainbow: Science, delusion, and the appetite for wonder. London: Penguin.

Dummett, M. (1981). Frege: Philosophy of language. London: Duckworth.

Gaskin, R. (2006). Experience and the world's own language. Oxford: Clarendon Press.

Gaskin, R. (2008). The unity of the proposition. Oxford: Oxford University Press.

Gaskin, R. (2009). Realism and the picture theory of meaning. Philosophical Topics, 37, 49-62.

Gaskin, R. (2013). When logical atomism met the Theaetetus: Ryle on naming and saying. In M. Beaney (Ed.), The Oxford handbook of the history of analytic philosophy (pp. 851-869). Oxford: Oxford University Press.

Gaskin, R. (2015). The identity theory of truth. http://plato.stanford.edu/entries/truth-identity/.

${ }^{26}$ See further Gaskin (2008, Chap. 2). 
Haddock, A. (2011). Davidson and idealism. In J. Smith \& P. Sullivan (Eds.), Transcendental philosophy and naturalism (pp. 26-41). Oxford: Oxford University Press.

Hale, B. (1987). Abstract objects. Oxford: Blackwell.

Hale, B. (2010). The bearable lightness of being. Axiomathes, 20, 399-422.

Hale, B., \& Wright, C. (2001). The reason's proper study: Essays towards a Neo-Fregean philosophy of mathematics. Oxford: Clarendon Press.

Heim, I., \& Kratzer, A. (1998). Semantics in generative grammar. Oxford: Blackwell.

Langendoen, D. T., \& Postal, P. (1984). The vastness of natural languages. Oxford: Blackwell.

Lewis, D. (1976). General semantics. In B. Partee (Ed.), Montague grammar (pp. 1-50). San Diego: Academic Press.

McDowell, J. (1994). Mind and world. Cambridge, MA: Harvard University Press.

McDowell, J. (1997). Brandom on representation and inference. Philosophy and Phenomenological Research, 57, 157-162.

McDowell, J. (1998a). Meaning, knowledge, and reality. Cambridge, MA: Harvard University Press.

McDowell, J. (1998b). The constitutive ideal of rationality: Davidson and Sellars. Crítica, 30, $29-48$.

Moore, A. (1997). Points of view. Oxford: Oxford University Press.

Morris, M. (2008). Wittgenstein and the Tractatus. London: Routledge.

Proops, I. (2004). Wittgenstein on the substance of the world. European Journal of Philosophy, 12, 106-126. Quine, W. V. (1960). Word and object. Cambridge, MA: MIT Press.

Quine, W. V. (1977). Facts of the matter. In R. Shahan \& K. Merrill (Eds.), American Philosophy: From Edwards to Quine (pp. 176-196). Norman: University of Oklahoma Press.

Schantz, R. (1996). Wahrheit, Referenz und Realismus. Berlin: Walter de Gruyter.

Sellars, W. (1963). Science, perception, and reality. New York: Humanities Press.

Simons, P. (1985). The old problem of complex and fact. Teoria, 5, 205-225.

Stenius, E. (1960). Wittgenstein's Tractatus: A critical exposition of the main lines of thought. Oxford: Blackwell.

White, R. (2006). Wittgenstein's Tractatus Logico-Philosophicus. London: Continuum.

Wittgenstein, L. (1922). Tractatus Logico-Philosophicus. London: Routledge.

Wittgenstein, L. (1973). Philosophische Grammatik. Frankfurt am Main: Suhrkamp.

Wittgenstein, L. (1977). Philosophische Untersuchungen. Frankfurt am Main: Suhrkamp (Trans. as Philosophical investigations, G. E. M. Anscombe. Oxford: Blackwell, 1958).

Wright, C. (1983). Frege's conception of numbers as objects. Aberdeen: Aberdeen University Press. 